University of Nebraska - Lincoln

DigitalCommons@University of Nebraska - Lincoln

\title{
A spatially explicit degree-day model of Rift Valley fever transmission risk in the continental United States
}

\author{
Sarah K. Konrad \\ University of Wyoming, skonrad@uwyo.edu \\ Scott N. Miller \\ University of Wyoming \\ Will K. Reeves \\ USDA-ARS-ABADRL
}

Follow this and additional works at: https://digitalcommons.unl.edu/usdaarsfacpub

\footnotetext{
Konrad, Sarah K.; Miller, Scott N.; and Reeves, Will K., "A spatially explicit degree-day model of Rift Valley fever transmission risk in the continental United States" (2011). Publications from USDA-ARS / UNL Faculty. 1308.

https://digitalcommons.unl.edu/usdaarsfacpub/1308
}

This Article is brought to you for free and open access by the U.S. Department of Agriculture: Agricultural Research Service, Lincoln, Nebraska at DigitalCommons@University of Nebraska - Lincoln. It has been accepted for inclusion in Publications from USDA-ARS / UNL Faculty by an authorized administrator of DigitalCommons@University of Nebraska - Lincoln. 


\title{
A spatially explicit degree-day model of Rift Valley fever transmission risk in the continental United States
}

\author{
Sarah K. Konrad · Scott N. Miller • \\ Will K. Reeves
}

Published online: 6 February 2010

(C) Springer Science+Business Media B.V. 2010

This article is a U.S. government work, and is not subject to copyright in the United States.

\begin{abstract}
A spatially explicit degree-day model was used to evaluate the risk of Rift Valley fever virus (RVFV) transmission by mosquitoes to humans and livestock within five target states in the continental United States: California, Minnesota, Nebraska, New York, and Texas. A geographic information system was used to model potential virus transmission based on a 12-day moving window assessment of the extrinsic incubation period theorized for RVFV in the United States. Risk of potential virus transmission in each state was spatially evaluated on a $10-\mathrm{km}$ grid using average historical daily temperature data from 1994 to 2003. The highest levels of transmission risk occur in California and Texas, with parts of these states at risk of RVFV transmission for up to 8 months per year. Northern Minnesota, central New York, and most of coastal and high-elevation California are at low to null risk. Risk of impact to the livestock industry is greatest in California, Texas, and Nebraska. A standard global climate model was used to evaluate future risk in the year 2030 in Nebraska, and showed an increase of transmission risk days from approximately 3 to 4 months per year.
\end{abstract}

S. K. Konrad $(\bowtie) \cdot$ S. N. Miller

University Wyoming, Laramie, WY, USA

e-mail: skonrad@uwyo.edu

W. K. Reeves

USDA-ARS-ABADRL, Laramie, WY, USA
Keywords Rift valley fever - Spatial analysis ·

Arbovirus · Mosquitoes

\section{Introduction}

Rift Valley fever virus (RVFV) (Bunyaviridae: Phlebovirus) is an insect-borne virus endemic to subSaharan Africa. A zoonotic disease, RVFV causes high mortality and abortion in domestic animals including cattle, sheep, and goats, and can cause viral hemorrhagic fever in humans (Geisbert and Jahrling 2004). Unlike most arboviruses that are transmitted by a limited number of vectors, RVFV has been associated with many different mosquito species and other biting flies (Meegan and Bailey 1988; Turell et al. 1996; Turell et al. 2008a, b), and it is likely that one or more North American mosquito species are potential competent vectors for RVFV. Should RVFV reach and become established within the continental US, it could have a devastating economic impact on the livestock industry, as well as create a serious health threat to humans (Pearson 2000). An exemplar for the potential establishment of RVFV in the US is West Nile virus (WNV), another arbovirus originating in Africa, which arrived in New York in 1999 and spread across North America within just a few years (Enserink 2002). A pathways analysis (Kasari et al. 2008) has identified regions of the United States that are most likely to see the introduction of RVFV. The goal of this study is to use GIS and degree-day modeling to 
identify where and when the virus is likely to disseminate in the US after introduction.

In Africa, RVFV epizootics are associated with periods of widespread and heavy rainfall, which lead to large populations of vector mosquitoes (Davies et al. 1985). The same association is true for WNV in Africa (Jupp 2001). Rainfall could play a similar role in the US, and researchers are conducting spatial risk evaluations based on this premise (Linthicum et al. 2007). However, the climatic differences between the generally temperate US and the variously tropical and arid sub-Saharan Africa suggest that temperature may play a more important limiting role in the US than in Africa. Temperature has been shown to be a good predictor of WNV transmission in the continental United States (Reisen et al. 2006; Konrad et al. 2009), whereas periods of extreme rainfall and flooding are not generally associated with outbreaks of arboviruses in the US (Nasci and Moore 1998). For these reasons, while we recognize other factors as contributing to transmission risk, in this study we focus on temperature as a necessary and limiting component in the cycle of RVFV transmission.

Previous research has shown a strong link between temperature and transmission of arboviruses by mosquito vectors (e.g., Hurlbut 1973; Reisen et al. 2006; Konrad et al. 2009). In order for the disease to be transmitted by the mosquito, the virus' extrinsic incubation period (EIP) must be completed. The EIP is the time between the ingestion of the virus by a biting arthropod to the time when the arthropod becomes infectious. The EIP is dependent on the genotype of the virus (Moudy et al. 2007), the mosquito species (e.g., Turell et al. 1985), and the temperature to which the mosquito is exposed during this period (e.g., Reisen et al. 2006). US winter temperatures and some northern or high elevation summer temperatures are likely too low for mosquitoes to complete the EIP. Although the EIP of RVFV in US mosquitoes is unknown, results from laboratory tests provide estimates of the temperature and time parameters necessary to quantify the transmission potential of US vectors.

Hosts of RVFV include domestic livestock, humans, wild ungulates, and potentially other unknown animals. While a plausible mechanism for entry into the US, humans are not considered major reservoirs of the disease, as they are quickly identified, isolated, treated, and are less accessible to vectors.
Livestock, primarily sheep and cattle, have been shown to be a major reservoir of RVFV, especially when concentrated together as in feedlots or herds (Meegan and Bailey 1988). Livestock are amplifying hosts of the virus: once they are infected, they serve to infect more mosquitoes or spread the virus via contaminated fluids. Areas of high livestock density, warmer temperatures, and an abundance of an appropriate mosquito species are presumed to be the most likely regions for RVFV to become established in the US.

Historical data provide a mechanism for examining past and present conditions suitable for disease establishment and transmission. However, variability in climate and evidence for increased temperatures due to global climate change imply that past data will underestimate virus transmission potential by underestimating the probability of exceeding the EIP in any given period of time. The relationship between higher temperatures and increased disease transmission (Patz et al. 1998) implies that global warming will increase the risk of RVFV becoming established in the US by putting more areas at risk for longer time periods. Although other aspects of climate change such as changes in precipitation amounts and patterns are also important, we restrict our research to the effect of changing temperatures using a global climate model.

This paper is intended as a thought-experiment to determine the most at-risk areas for RVFV becoming established in the continental US. Analyses are conducted for five states spatially distributed across the country, four of which (California, Minnesota, New York, and Texas) are deemed to be at a high level of RVFV introduction risk through the pathways analysis (Kasari et al. 2008), and the fifth (Nebraska) is a centrally located state with a large livestock industry. Not every potential risk factor is examined; notably lacking are the factors of precipitation, vector mosquito populations, and presence of suitable vector breeding habitat. We use the critical and limiting factor of temperature as a proxy for virus transmission risk, and livestock density to assess areas of likely establishment and impact. Other analyses such as the link between rainfall, the normalized difference vegetation index (NDVI), and vector mosquito abundance are being concurrently conducted by other researchers within the RVFV Working Group (Linthicum et al. 2007); the intention is that the findings of all studies be used together to best assess risk and subsequent preventative measures. 


\section{Materials and methods}

Degree-day modeling

In this project we improved upon a publicly available geographic information system (GIS) tool that estimates the risk of arbovirus transmission based on a degree-day model (Zou et al. 2007; Konrad et al. 2009). The original tool works by assessing spatial and temporal temperature data to determine when and where the virus EIP is completed within the duration of the mosquito vector's feeding period. As the tool uses data from local weather stations, it is best suited for point analysis. In order to perform a broader spatial analysis, interpolation among the weather stations is necessary. Simple interpolation techniques such as inverse-distance weighting prove adequate at small scales where the topography and climate are somewhat homogenous (Konrad et al. 2009). For larger scales, a method that interpolates temperatures between weather stations while taking into account topography and other climatic influences is required. The DAYMET database (www.daymet.org, Thornton et al. 1997) provides temperature maxima and minima interpolated to a 1-km grid spanning most of the contiguous United States on a daily basis from 1980 to 2003 .

In order to take advantage of the resources of the DAYMET database and provide a more fully spatially explicit modeling framework, we created a new GISbased degree-day tool to work with the large amounts of spatial and temporal data available. The primary procedures followed by the tool are schematically illustrated in Fig. 1. User inputs include: the length of the vector feeding period (the time between the mosquitos's first and last blood meal), the degreedays until EIP for the virus and vector in question, the minimum transmission threshold temperature, and daily temperature maxima and minima for the time period and region of interest. HydroGET (http://his. cuahsi.org/hydroget.html), a web service client for ArcGIS developed by the Consortium of Universities for Advancement of Hydrologic Science, is used to download daily temperature minima and maxima from DAYMET. The temperature data are run through the degree-day equations, generating a degree-day temperature for each day at each point on the spatial grid. The total degree-days occurring during the vector feeding period are calculated by adding the individual degree-days within the specified period up to the date of interest. For example, if the vector feeding period were 10 days, then the total degree-days on July 24 would be the sum of the degree-days from July 15 . This degree-day total is then compared to the required minimum number of degree-days until EIP: if greater, than the grid square for that day is deemed at risk of RVFV transmission, and if lower, the grid square is not at risk.

The degree-days necessary to reach EIP are strongly dependent on both the nature of the virus and the species of mosquito. As RVFV has not been introduced to the US nor have there been comprehensive studies of the relationship between RVFV and the 174 known US mosquito species, these parameters must be quantified by laboratory work. Out of eight likely vectors tested to date, Culex tarsalis has proved to be the most effective RVFV vector (Turell et al. 2008a, b), and therefore the best mosquito species to use as a model of RVFV transmission risk in the United States. Unfortunately, the relationship between temperature and transmission rates of RVFV in $C x$. tarsalis has not yet been quantified. In the absence of this data, a "best guess" is that $C x$. tarsalis infected with RVFV will respond to temperature at a rate similar to $C x$. tarsalis infected with West Nile virus (M. J. Turell, pers. comm. 2009). These parameters have already been established in California: 76 degree-days to reach EIP with a minimum transmission temperature of $14.3^{\circ} \mathrm{C}$ (Konrad et al. 2009) and 12 days between the first and last blood meal (the sum of three-four-day gonotrophic cycles: after Reisen et al. 1993). The EIP of several other species of mosquitoes infected with RVFV have been tested at various temperatures, allowing the derivation of the degree-day parameter for colonized Egyptian Culex pipiens (111 DD, after Turell et al. 1985), colonized North American Aedes taeniorhynchus (175 DD, after Turell et al. 1985), and colonized Senegalese Aedes fowleri (175 DD, after Turell 1989). These rates are all slower than the 76 DD "best guess" parameter, suggesting that this study is more likely to overestimate rather than underestimate risk, which is beneficial from a conservative management perspective.

Livestock population

Livestock data from the 2002 census were downloaded from the United States Department of Agriculture 
Fig. 1 Schematic of degree-day model application. Equations after Allen (1976)

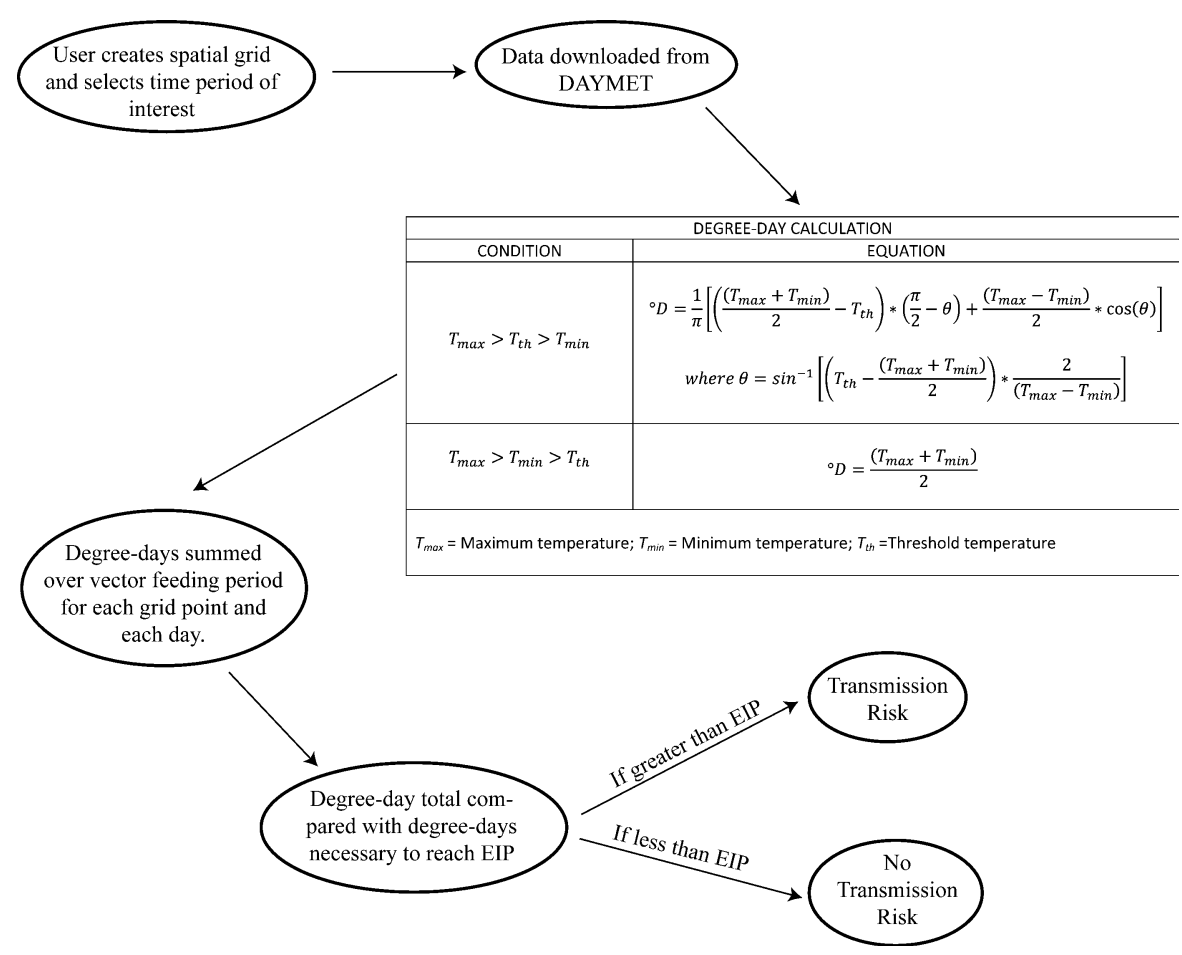

National Agricultural Statistics Service (USDANASS, www.nass.usda.gov). Total cattle and calf, sheep and lamb, and goat populations were downloaded at the county level. If a county has only a few farms, USDA-NASS withholds the county population numbers. However, as total populations in each state are available, the number of livestock in the unreported counties can be back-calculated. This number was apportioned to the unreported counties in proportion to the number of farms in each county. Total livestock densities (cattle, sheep, and goats) are shown in Fig. 2.

\section{Risk modeling}

HydroGET was used to download 10 years of daily temperature minima and maxima from DAYMET (January 1, 1994 to December 31, 2003) for the target states on a $10-\mathrm{km}$ spatial grid. These temperatures were compiled to provide the 10 -year daily average maximum and minimum temperatures at each grid point. The degree-day tool (Fig. 1) was used to determine the temperature-based transmission risk of every $10-\mathrm{km}$ square for every day of the year based off of mean historical temperatures from 1994 to 2003.
The most at-risk areas for the establishment and subsequent economic impact of RVFV are those where the mosquito vectors are present, the degreeday temperatures are high enough for the virus to reach EIP in the host mosquitoes for a relatively large number of days, and there is a large concentration of livestock hosts. Degree-day temperatures reflect only the risk of RVFV transmission, but the greater the livestock density in RVFV risk areas, the greater the potential economic impact to the livestock industry and the higher the chances for the establishment of RVFV in a domestic animal reservoir. Therefore, we evaluate both transmission risk and compound risk, which we assess by normalizing both the number of transmission risk days per year and the livestock density on linear scales, summing these and mapping them onto a zero to one compound risk scale. If the degree-days are never warm enough (zero risk days), the compound risk is also assumed to be zero.

Future climate scenario

Downscaled future temperature data were obtained from the World Climate Research Programme Coupled Model Intercomparison Project (http://gdo-dcp. ucllnl.org/downscaled_cmip3_projections/depInterfa 
Fig. 2 Livestock density by US county (data from USDA-NASS)

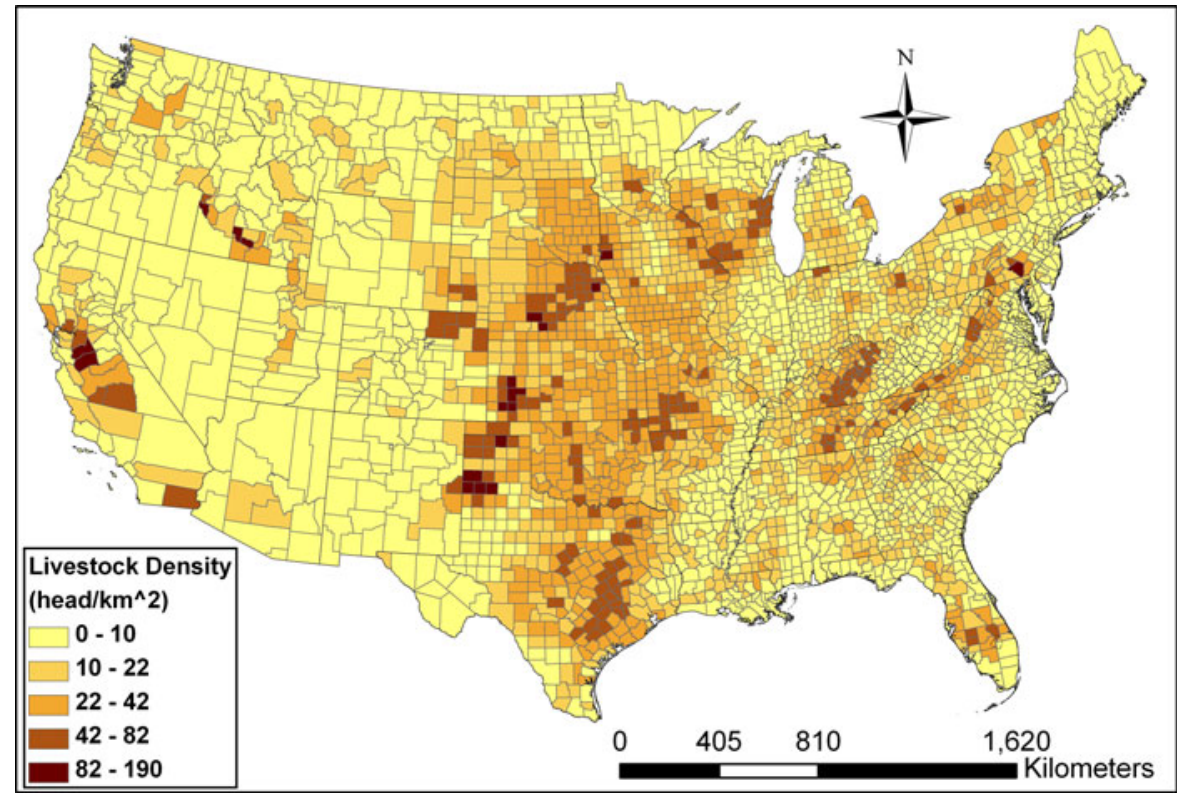

ce.html). These data are available on a monthly basis through 2099 and have been statistically downscaled to a $12-\mathrm{km}$ resolution (Maurer 2007). The year 2030 was chosen to represent a time both far enough in the future to show significant change and close enough to the current year to be meaningful for risk assessment. The often used UKMO global climate model (GCM) was used in conjunction with the SRES A1B emission scenario, which represents a "business as usual" future (IPCC 2007). Monthly average temperature for each of the summer arbovirus transmission months (June, July, August, and September) were downloaded for Nebraska, the most centrally located of the study states.

As the GCMs only provide average monthly temperatures rather than the daily temperature maxima and minima needed for the degree-day analysis of RVFV transmissivity, future maximum and minimum temperatures were derived from the GCM data. Points were generated in a regular array every 0.125 degrees across Nebraska to match the resolution of the GCM data, resulting in 1374 data points. Ten years of DAYMET data were downloaded for these points as described above in the degree-day modeling methodology. We reduced the historical temperature data to 10 -year mean maxima and minima for each month. We then used these values to calculate median monthly temperatures, which were compared to the average monthly temperatures predicted by the GCM. Monthly maxima and minima were calculated for the GCM data by applying the difference between the extreme temperatures and the median temperatures of the historical data to the GCM data. For example, if historical July maximum and minimum temperatures were $30^{\circ} \mathrm{C}$ and $16^{\circ} \mathrm{C}$, respectively, with a median temperature of $23^{\circ} \mathrm{C}$, the corresponding maximum and minimum temperatures for the same point in the GCM are found by adding and subtracting $7^{\circ} \mathrm{C}$ to the GCM average temperature.

RVFV risk was evaluated with the degree-day tool using future maxima and minimum temperatures for each month. As daily GCM data is unavailable, every day in the month was assumed to have the same maximum and minimum temperatures.

\section{Results and discussion}

Transmission risk can be visualized by day (Fig. 3) or cumulatively as the number of risk days per year at each point (Fig. 4). Risk evaluation at the day level will be useful to determine action areas if RVFV has already reached the country; the number of risk days per year is ideal for assessing regional risk before RVFV has reached the country and the introduction point is unknown. The southern portions of Texas and California have the greatest temperature-based transmission 
risk of the target states, and are at risk for almost 8 months of the year (approximately March through November). There are lower levels of risk (1-4 months) in the northern portions of Texas and California, Nebraska, southern Minnesota, and southeastern and northwestern New York.

The modeling effort presented here can be analyzed either at a particular station or across a larger spatial domain. For example, Fig. 3 illustrates the changing pattern of RVFV through time in the five target states. In this example, representative dates are chosen to demonstrate the increasing range of potential RVFV as the EIP threshold is exceeded over an increasing area through the summer, and then diminishing as fall approaches. While $100 \%$ of both Nebraska and Texas exceed the EIP threshold during the summer, Fig. 3 shows that the risk for transmission is extended throughout the year in Texas, while in Nebraska it is limited to a shorter duration in late summer. The southern parts of Texas and California maintain high enough temperatures to exceed the EIP threshold for the majority of the year; these results are further highlighted in Fig. 4 where portions of those states have over 200 days per year in which the EIP threshold is exceeded. Large swaths of upstate Minnesota and New York, coastal, northern, and mountainous areas of California are identified as low to minimal risk. This spatial analysis identifies "hot spots" where the virus is more likely to establish itself due to the longer periods of potential virus transmission, which magnify the potential for reservoir hosts to become established.

Given the release of RVFV into a susceptible livestock population in the five target states evaluated in this degree-day model, these results highlight the changing pattern of RVFV availability, particularly as a function of the time of year, for potential transmission from mosquito vectors to susceptible livestock hosts. Risk of virus outbreak and establishment is minimized during those periods when the EIP threshold is not exceeded, but increases as temperature increases and days are continually exceeding the threshold.

A complementary way to assess the risk in the target states is with a cumulative distribution function (Fig. 5). The states with the highest levels of risk fall on the right side of the chart, and the states with the lowest on the left. States that have a wide range across the horizontal axis (like California) are climatically diverse, with diverse risk levels, whereas states that map onto only a small portion of the horizontal axis (like Nebraska) are relatively homogenous. Figure 5 clearly shows that Texas is the state with the greatest potential risk; the entire state has over 90 days in which the EIP is exceeded, and the area with the greatest number of exceedence days (243). In both the current climate and future climate scenarios the entire state of Nebraska is at risk, with
Fig. 3 Four sample days showing the risk of RVFV transmission based upon the local average degree-day temperatures: light gray represents areas deemed not to be at risk; dark gray are areas at risk of RVFV transmission

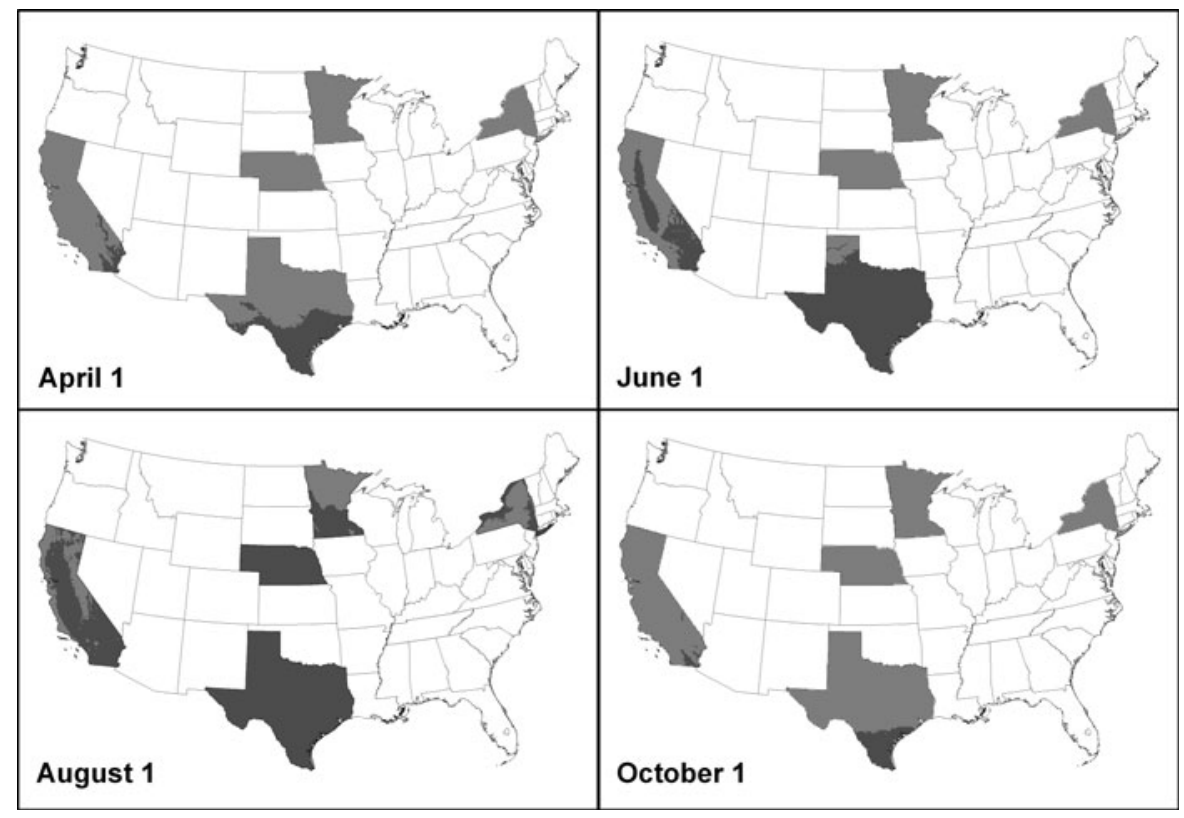


Fig. 4 Total temperaturebased transmission risk days over the course of a year

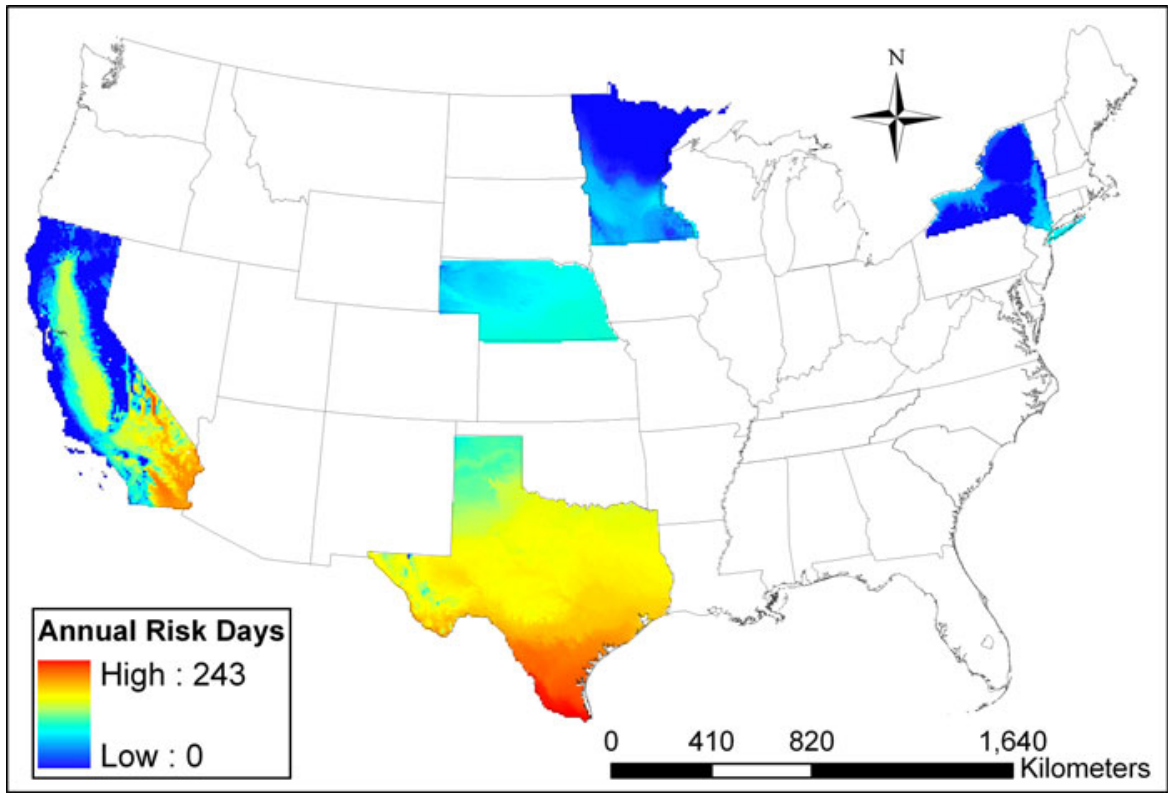

an increase of more than a month in the number of risk days due to increased temperatures associated with global climate change (from a state-wide average of 79 risk-days to 118 risk-days). High percentages of New York and Minnesota (NY: 58\%; MN: 44\%) have zero risk days, while the remainder of these two states are under 100 risk days per year. California is the most diverse state, with approximately $30 \%$ of the state at minimal risk of transmission, but some portions of the state experiencing over 200 risk days per year.

Risk is further visualized as the percentage of state area subjected to various levels of risk in Fig. 6: low risk (a month or less), moderate risk (between 1 and 3 months) and high risk (over 3 months). This method allows the states to be ranked from lowest to highest RVFV risk: New York, Minnesota, California, Nebraska, and finally Texas. Figure 6 also shows how simulated climate change in 2030 pushes the entire state of Nebraska into high risk category.

Spatially explicit results such as those presented in Figs. 3 and 4 show the relative connectedness of areas that are at higher risk of virus transmission. Larger swaths of higher EIP exceedence are deemed at highest risk and may deserve greater attention for management and control of disease outbreaks. These results are combined with livestock densities to

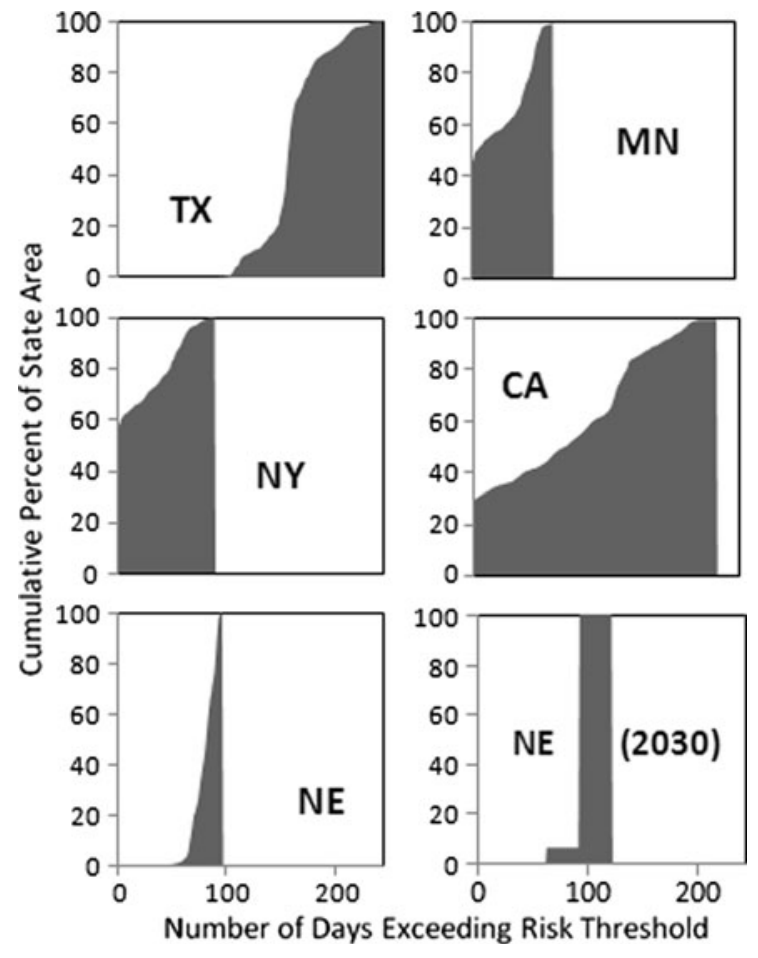

Fig. 5 Cumulative distribution function of RVFV risk in the target states as a function of percentage of the state area. Nebraska is plotted twice, based on the historical temperatures (as with the other states) and with future temperature predicted for the year 2030 based on a global climate model 


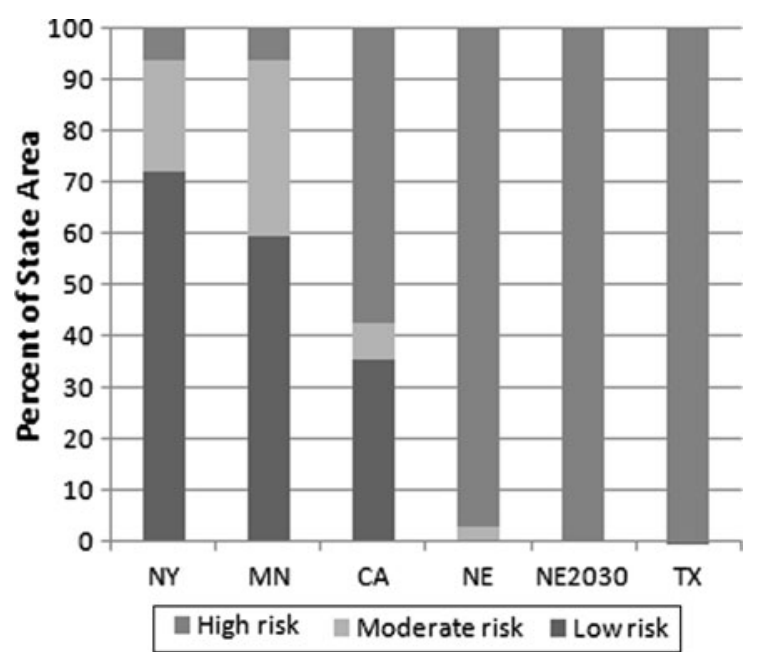

Fig. 6 Percentage of state area at low risk (less than a month), moderate risk (1-3 months), and high risk (greater than 3 months): New York (72\% low, 22\% moderate, 6\% high), Minnesota (60\% low, 34\% moderate, 6\% high), California (36\% low, $7 \%$ moderate, $57 \%$ high), Nebraska (3\% moderate, $97 \%$ high), Nebraska in 2030 (100\% high), Texas (100\% high)

produce a compound risk map in Fig. 7. Livestock density is highest in the central US states including Nebraska and Texas and the Central Valley of California (Fig. 2). If the temperatures are high in a region with few livestock, the relative risk is low, as it is where the livestock numbers are high but the temperatures are low. If the temperatures are moderate and there are an average number of livestock, the relative risk will be higher, and will continue to increase with temperature and/or livestock density. In order to represent compound risk, the number of risk days and the livestock density were normalized on linear scales spanning both data ranges (from 0 to 243 days and 0-190 animals $/ \mathrm{km}^{2}$, respectively). These were summed and mapped onto a zero to one risk scale. If the degree-days are never warm enough (zero risk days), the relative risk is also assumed to be zero.

The areas of greatest compound risk are Southern Texas, the Texas Panhandle, regions in Nebraska of high livestock density, and the Central Valley and most southern region of California. We consider any area that has more than one day where the EIP threshold is exceeded to have some risk of RVFV transmission; however, Fig. 7 shows how risk is amplified where livestock are present in high densities. Thus, while the entirety of Texas is at risk, the southern areas and the Panhandle are at elevated risk due to high livestock densities (Fig. 2). These risk maps are created for each day in the year by combining results shown in Fig. 3 with the livestock density data of Fig. 2, and provide a more temporal analysis of risk that would be useful to managers tasked with tracking and controlling an outbreak. If Cx. tarsalis does indeed become the dominant or sole RVFV vector in the US, areas not within the established range of $C x$. tarsalis (including New York) may be subject to lower risk than that predicted by the model (Fig. 7).

In addition to California, Texas, New York, and Minnesota, the other states identified by pathways analysis as being at elevated risk for the introduction of RVFV are Alabama, Florida, Georgia, Maine, Maryland, Massachusetts, New Jersey, Pennsylvania, South Carolina, and Virginia (Kasari et al. 2008). Evaluation of risk in these states through degree-day analysis is beyond the scope of this project; however, extrapolation from the target states suggest that the southern states (Alabama, Florida, Georgia, Virginia, Maryland, and South Carolina) have moderate levels of risk, as they are warm and have significant but not extremely dense livestock populations. New Jersey and Pennsylvania likely have low levels of risk, and the far northern states of Massachusetts and Maine probably have minimal risk.

Global warming will contribute significantly to risk, both by lengthening the risk time period in areas already deemed to be at risk, and by introducing risk to areas that were previously too cold. Analysis of the GCM data for Nebraska shows a lengthening of the risk season (Table 1). Almost twice as much of Nebraska is projected to be at risk in June in 2030 compared with the 1994-2003 historical averages. In addition, in the future model, risk persists into September in southeastern Nebraska, whereas the historical averages predict no September RVFV risk in Nebraska. The cumulative distribution function of Nebraska in 2030 (Fig. 5) shows approximately an additional month of risk across the state than estimated for the historical temperatures.

This study only examines two critical and limiting factors associated with RVFV risk, those of EIP exceedence and the presence of potential reservoirs for virus establishment. The study will be most useful when combined with other risk analyses, such as one currently undertaken involving spatial and temporal 
Fig. 7 Normalized risk based on both degree-days and livestock populations. Range of Culex tarsalis after Darsie and Ward 2005

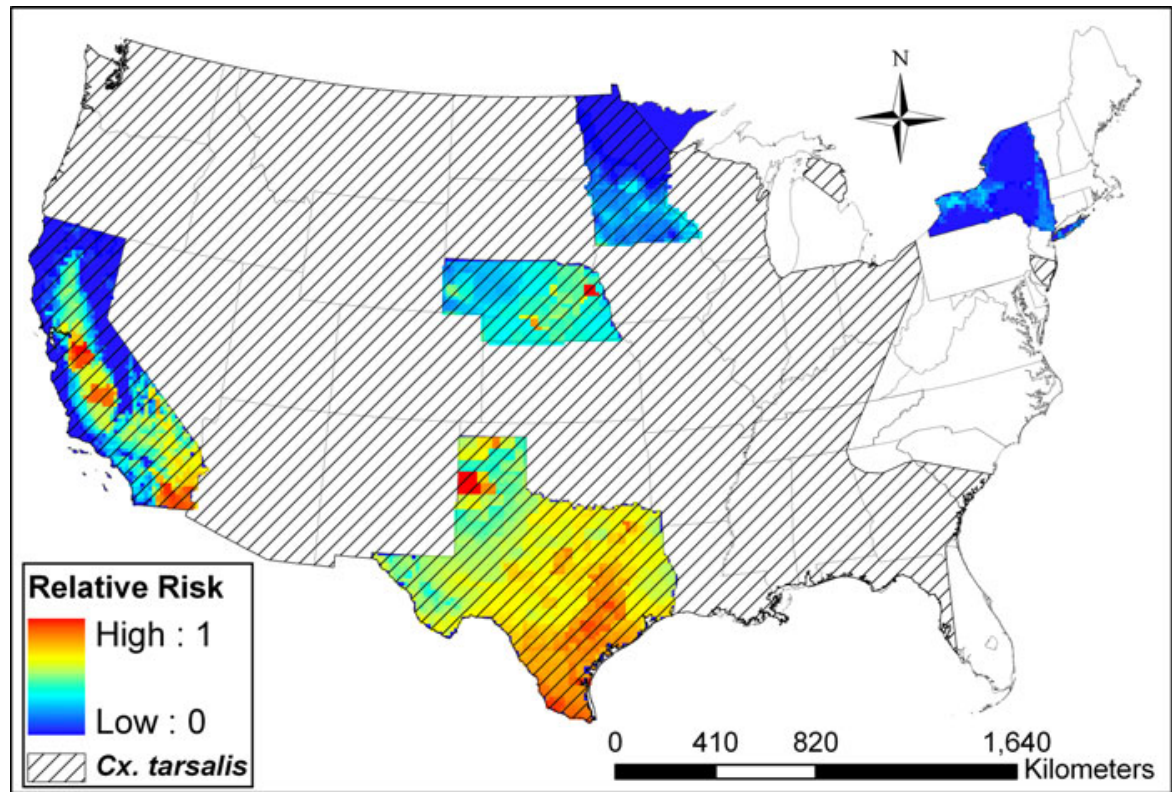

Table 1 Percent of Nebraska's land area at risk of RVFV transmission (at or above the threshold EIP of 76 degree-days) determined on a monthly basis

\begin{tabular}{lcc}
\hline Month & $\begin{array}{l}\text { At risk land area based } \\
\text { on 1994-2003 } \\
\text { average temperatures } \\
(\%)\end{array}$ & $\begin{array}{l}\text { At risk land area } \\
\text { based on GCM } \\
\text { model temperatures } \\
\text { for 2030 }(\%)\end{array}$ \\
\hline June & 47 & 90 \\
July & 100 & 100 \\
August & 100 & 100 \\
September & 0 & 7 \\
\hline
\end{tabular}

analysis of mosquito populations and the normalized difference vegetation index, NDVI (Linthicum et al. 2007). One of the strengths of this study is $10-\mathrm{km}$ grid scale of the temperature analysis which allows for detailed risk prediction by capturing small-scale climatic variations. We used $C x$. tarsalis as a model RVFV vector in the US, but other mosquito species may be important for disease transmission. It is likely that the degree-day parameters used in this study will need to be modified as future laboratory and field work empirically determine the relationship between temperature and time in $C x$. tarsalis and other potential vectors. However, such modification is straightforward to perform, and the existing temperature database can be used to examine risk with different temperature-based parameters.
Acknowledgments This project was funded by a USDA specific cooperative agreement \#5410-32000-014-15. The use of trade names in this document does not constitute an official endorsement or approval of the use of such commercial hardware or software. Do not cite this document for advertisement.

\section{References}

Allen, J. C. (1976). A modified sine wave method for calculating degree-days. Environmental Entomology, 5(3), 388-396.

Darsie, R. F., Jr., \& Ward, R. A. (2005). Identification and geographical distribution of the mosquitoes of North America North of Mexico. Gainesville: Universtiy Press of Florida. 348 p.

Davies, F. G., Linthicum, K. J., \& James, A. D. (1985). Rainfall and epizootic Rift Valley Fever. Bulletin of the World Health Organization, 63(5), 941-943.

Enserink, M. (2002). West Nile's surprisingly swift continental sweep. Science, 297(5589), 1988-1989.

Geisbert, T. W., \& Jahrling, P. B. (2004). Exotic emerging viral diseases: progress and challenges. Nature Medicine, 10(12), S110-S1221.

Hurlbut, H. S. (1973). The effect of environmental temperature upon the transmission of St. Louis encephalitis virus by Culex pipiens quinauefasciatus. Journal of Medical Entomology, 10(1), 1-12.

Intergovernmental Panel on Climate Change (IPCC). (2007). Climate change 2007: the physical science basis. Contribution of Working Group I to the Fourth Assessment Report of the Intergovernmental Panel on Climate Change. http://ipcc-wg1.ucar.edu/wg1/wg1-report.html. Accessed December 31, 2008. 
Jupp, P. G. (2001). The ecology of West Nile virus in South Africa and the occurrence of outbreaks in humans. Annals of the New York Academy of Sciences, 951, 143-152.

Kasari, T. R., Carr, D. A., Lynn, T. V., \& Weaver, J. T. (2008). Evaluation of pathways for release of Rift Valley fever virus into domestic ruminant livestock, ruminant wildlife, and human populations in the continental United States. Journal of the American Veterinary Medical Association, 232(4), 514-529.

Konrad, S. K., Miller, S. N., Reeves, W. K., \& Tietze, N. S. (2009). Spatially explicit West Nile virus risk modeling in Santa Clara County, CA. Vector-Borne and Zoonotic Diseases, 9(3), 267-274.

Linthicum, K. J., Anyamba, A., Britch, S. C., Chretien, J. P., Erickson, R. L., Small, J., et al. (2007). A Rift Valley fever risk surveillance system for Africa using remotely sensed data: potential for use on other continents. Veterinaria Italiana, 43(3), 663-674.

Maurer, E. P. (2007). Uncertainty in hydrologic impacts of climate change in the Sierra Nevada, California under two emissions scenarios. Climatic Change, 82(3-4), 309-325.

Meegan, J. M., \& Bailey, C. L. (1988). Rift Valley fever. In T. Monath (Ed.), Arboviruses: Epidemiology and ecology (Vol. IV, pp. 51-76). Boca Raton, FL: CRC Press.

Moudy, R. M., Meola, M. A., Morin, L. L., Ebel, G. D., \& Kramer, L. D. (2007). A newly emergent genotype of West Nile virus is transmitted earlier and more efficiently by Culex mosquitoes. American Journal of Tropical Medicine and Hygiene, 77, 365-370.

Nasci, R. S., \& Moore, C. G. (1998). Vector-borne disease surveillance and natural disasters. Emerging Infectious Diseases, 4(2), 333-334.

Patz, J. A., Martens, W. J. M., Focks, D. A., \& Jetten, T. H. (1998). Dengue fever epidemic potential as projected by general circulation models of global climate change. Environmental Health Perspectives, 106(3), 147-153.

Pearson, J. E. (2000). Biological agents as potential weapons against animals. Biological warfare technical brief, 16 June 2000. Office International des Epizooties (OIE), Paris, 3 p.
Reisen, W. K., Fang, Y., \& Martinez, V. M. (2006). Effects of temperature on the transmission of West Nile virus by Culex tarsalis (Diptera: Culicidae). Journal of Medical Entomology, 43(2), 309-317.

Reisen, W. K., Meyer, R. P., Presser, S. B., \& Hardy, J. L. (1993). Effect of temperature on the transmission of western equine encephalomyelitis and St. Louis encephalitis viruses by Culex tarsalis (Diptera: Culicidae). Journal of Medical Entomology, 30(1), 151-160.

Thornton, P. E., Running, S. W., \& White, M. A. (1997). Generating surfaces of daily meteorology variables over large regions of complex terrain. Journal of Hydrology, 190(3-4), 214-251.

Turell, M. J. (1989). Effect of environmental temperature on the vector competence of Aedes fowleri for Rift Valley fever virus. Research in Virology, 140(2), 147-154.

Turell, M. J., Bennett, K. E., Wilson, W. C. (2008a). Potential for North American Mosquitoes to Transmit Rift Valley Fever Virus. Poster presented at the American Society for Tropical Medicine and Hygiene conference, New Orleans, LA, December 2008.

Turell, M. J., Linthicum, K. J., Patrican, L. A., Davies, F. G., Kairo, A., \& Bailey, C. L. (2008b). Vector competence of selected African mosquito (Diptera: Culicidae) species for Rift Valley fever virus. Journal of Medical Entomology, 45(1), 102-108.

Turell, M. J., Presley, S. M., Gad, A. M., Cope, S. E., Dohm, D. J., Morrill, J. C., et al. (1996). Vector competence of Egyptian mosquitoes for Rift Valley fever virus. American Journal of Tropical Medicine and Hygiene, 54(2), 136-139.

Turell, M. J., Rossi, C. A., \& Bailey, C. L. (1985). Effect of extrinsic incubation temperature on the ability of Aedes taeniorhynchus and Culex pipiens to transmit Rift Valley fever virus. American Journal of Tropical Medicine and Hygiene, 34(6), 1211-1218.

Zou, L., Miller, S. N., \& Schmidtmann, E. T. (2007). A GIS tool to estimate West Nile virus risk based on a degreeday model. Environmental Monitoring Assessment, 129(1-3), 413-420. 